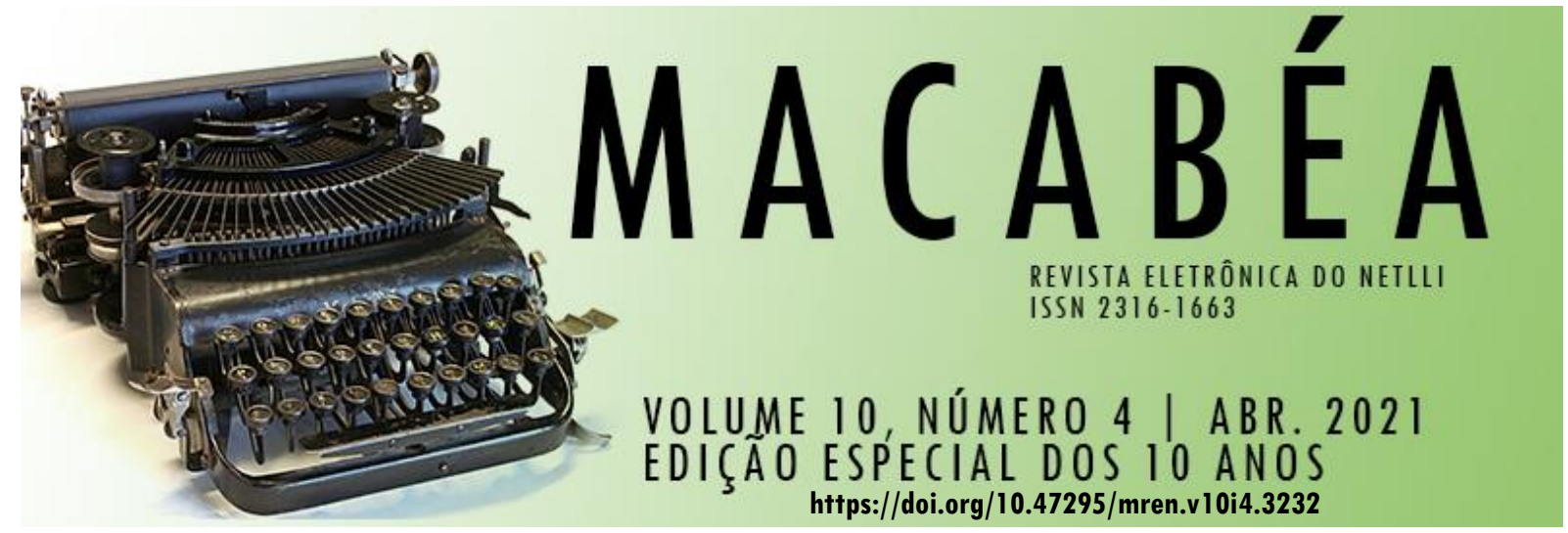

\title{
OS DESAFIOS DA FILOLOGIA NO ROMANCE HISTÓRIA DA DONZELA TEODORA
}

\section{THE CHALLENGES OF PHILOLOGY IN STRING LITERATURE HISTÓRIA DA DONZELA TEODORA}

JODIE ELLY SILVA GOMES

\author{
RESUMO | INDEXAÇ̃̃O | TEXTO | REFERÊNCIAS | CITAR ESTE ARTIGO | A AUTORA \\ RECEBIDO EM 20/02/2021 • APROVADO EM 08/03/2021
}

\begin{abstract}
This article aims to analyze the challenges of philology identified in three editions of folheto História da Donzela Teodora. It is important to reflect, initially, about the object of study of philology, according to Cambraia (2005) and Spina (1977), so that there is no doubt that the String Literature can be used as a corpus of this research. Also, we will demonstrate, through passages taken from the folheto, the continuum between the oral and the written genre, of which Porter (1993) speaks. We selected, in turn, some challenges, based on Cambraia's studies (2005), that were relevant to the investigation, which are the time when the text was produced, the language used in the three editions and the corruption of the material.
\end{abstract}

\section{Resumo}

Este artigo pretende analisar os desafios da filologia identificados em três edições do folheto História da Donzela Teodora. É importante refletir, inicialmente, sobre o objeto de estudo da filologia, de acordo com Cambraia (2005) e Spina (1977), para que não restem dúvidas de que a literatura de folhetos pode ser utilizada como corpus dessa pesquisa. Ainda, demonstraremos, através de passagens extraídas do folheto, 0 continuum entre 0 gênero oral e 0 gênero escrito, do qual Porter (1993) fala. Selecionamos, por sua vez, alguns desafios, 
com base nos estudos de Cambraia (2005), que foram relevantes para a investigação, quais sejam a época em que 0 texto foi produzido, a linguagem utilizada nas três edições e a corrup̧̧ão do material.

\section{Entradas para indexação}

KEYWORDS: Philology. Challenges. String Literature. História da Donzela Teodora.

PALAVRAS-CHAVE: Filologia. Desafios. Literatura de Folheto. História da Donzela Teodora.

\section{Texto integral}

\section{INTRODUÇÃO}

O folheto História da Donzela Teodora, escrito e editorado por Leandro Gomes de Barros, não possui referência a ano e lugar nos exemplares de sua primeira edição. De acordo com Silva (2019), Barros abriu uma pequena gráfica em 19071, onde passou a produzir sua literatura de folhetos. Com o tempo, logo os folhetos se espalharam por todo o Nordeste. Apesar de existir farta documentação sobre a atividade editorial de Leandro Gomes de Barros, não se pode afirmar com precisão quando foi a primeira publicação do folheto. Assim, nosso corpus para este estudo é composto pelo folheto História da Donzela Teodora a partir de três edições: a escrita e editorada por Leandro Gomes de Barros (19--a), a editorada por José Bernardo da Silva (19--b) e a editorada por João Martins de Athayde (1947).

Barros (19--a, p. 32) afirma, nos últimos versos do poema, que todas as informações foram retiradas de um livro que serviu de consulta e que ele só teria feito rimar a história. A partir dessa informação, constatamos que a História da Donzela Teodora muito se assemelha com aquela contada na Historia de La Docta Simpatía, presente no livro Las Mil y Una Noches, versão de Mardrus, traduzida para o espanhol por Vicente Blasco Ibáñez (1916). Não podemos deixar de mencionar a primeira edição portuguesa dessa história, que é intitulada História da Donzella Theodora em que se trata da sua grande fermosura e sabedoria (1740), traduzida por Carlos Ferreira Lisbonense, que conta a história da Donzela em prosa.

Antes de abordar os desafios da filologia para análise do folheto, propomos uma reflexão sobre a arte filológica a partir de sua definição. Auerbach (1970) afirma que a filologia se ocupa da linguagem de diversas maneiras e que ela abrange inúmeras atividades. Essa ciência seria um conjunto de atividades que tratam da linguagem de uma sociedade e de suas obras de arte escritas nessa linguagem. Assim, a filologia não só estudaria a língua, o texto em si, mas todas as características

\footnotetext{
${ }^{1}$ Leandro Gomes de Barros publicava seus poemas em folhetos desde 1893, de acordo com Terra (1983, p. 17 apud AYALA, 2016, p. 13) e o período em que a sua gráfica foi aberta ainda é controverso, mas estudos de Silva (2019) e de Vianna (2014) apontam os anos de 1907 até 1913 como o período de funcionamento da gráfica. A Fundação Casa de Rui Barbosa informa o ano de 1906.
} 
que podem ser auferidas do documento analisado, como a cultura de uma sociedade ou a revelação do verdadeiro autor de uma obra.

Ainda, para efeito de descrição do método aqui empregado, julgamos necessário assegurar que é perfeitamente válida a análise do corpus à luz de preceitos filológicos, principalmente no tocante à função adjetiva da filologia. Para isto, selecionamos três desafios a serem analisados, que são a época em que o texto foi produzido, a linguagem utilizada e a corrupção do material. Cada desafio possui seus desdobramentos e utilizaremos imagens de cada folheto para melhor exemplificar os processos que pretendemos demonstrar.

\section{ARTE FILOLÓGICA: DOS GÊNEROS ORAIS AOS GÊNEROS ESCRITOS}

Das muitas definições que orbitam o termo filologia, adotaremos aquela que a define como o estudo global de um texto, uma exploração exaustiva e conjunta de suas características, quais sejam a linguística, a literária, a crítico-textual e a sóciohistórica, de acordo com o pensamento de Cambraia (2005). À vista disso, tentaremos analisar o corpus diante dessa análise filológica exaustiva, que leva em consideração todos os aspectos que compõem esse texto, mais notadamente a época, a linguagem e a corrupção do material, e pretendemos explorar as características linguísticas, literárias e históricas que podem nos ajudar na análise do corpus. Para essa análise, precisamos entender as modificações que um texto pode sofrer, pois assumimos que todo texto é passível de modificação, devido ao processo de transmissão pelo qual passa, e essa modificação divide-se em duas categorias, conforme Cambraia (2005): a endógena e a exógena.

As modificações endógenas caracterizam-se pela passagem do material original para um outro suporte de material, o processo do original para a cópia. A origem dessa modificação reside no processo interno ao ato da cópia, ou seja, depende do responsável que realiza a modificação. Ela pode ser dividida em autoral e não autoral. Esta é realizada por terceiros que não possuem autorização do autor da obra, que sequer tem conhecimento dessa modificação e aquela é realizada pelo próprio autor, seja no momento da revisão, seja a pedido de editores, antes ou após a primeira impressão do texto. As modificações não-autorais possuem duas subdivisões, as voluntárias e involuntárias, sendo que estas ocorrem por lapso de quem reproduz o texto. Tradicionalmente a isto chama-se de erro de cópia, enquanto as modificações voluntárias ocorrem por ato consciente de quem reproduz o texto (CAMBRAIA, 2005).

As modificações exógenas, por sua vez, resultam da corrupção do material que foi utilizado para registrar o texto, inclusive as corrupções que acontecem em razão do decorrer do tempo. A corrupção do material pode acontecer por vários motivos, desde motivos típicos, como a umidade, o calor, até motivos atípicos, como o vandalismo (CAMBRAIA, 2005). Algumas dessas modificações podem ser encontradas no corpus, como, por exemplo, a corrupção do material devido a fatores típicos/naturais, como demonstraremos mais adiante. Importa-nos, agora, refletir como a literatura de folhetos, que possui traços de oralidade, pode ser objeto da análise filológica, nesse fio de transmissão que liga os gêneros orais e escritos. 
A literatura de folheto possui traços da oralidade e, de acordo com Zumthor (1993), existem três tipos de oralidade: a primária e imediata; a oralidade mista e a oralidade segunda. A oralidade primária e imediata é aquela que não guarda nenhum contato com a escrita e só podemos encontrá-la em sociedades que não contam com nenhum sistema de simbolização gráfica. A oralidade mista, por sua vez, coexiste com a escritura, mas a influência desta permanece externa, parcial e atrasada. A oralidade segunda se reorganiza com base na escritura, em que esta tem a intenção de esgotar os valores da voz no uso e no imaginário. Diante dessas classificações propostas por Zumthor, constatamos que a literatura de folheto se encaixaria como oralidade mista, uma vez que já existe uma cultura escrita, mas esta não é predominante. Em nossa leitura, os traços da oralidade, que são estruturantes da forma poética nessa literatura, sofrem o efeito da proximidade como sistemas literários baseados na palavra escrita, que no caso da literatura nordestina de folhetos, deve ser entendida como suporte e não como material da linguagem poética.

O objeto de análise da filologia é o texto e não a tradição oral, e o objeto de análise desse trabalho pertence à literatura de folheto que pode ser entendida como resultado da oralidade mista ou como literatura oral cujo suporte é o texto escrito. Dessa forma, é perfeitamente adequado utilizar a arte filológica para fazermos uma exploração do texto e isso se justifica pelo elemento transdisciplinar que a filologia possui, já que engloba várias disciplinas auxiliares para desvendar pontos indecifráveis do texto (SPINA, 1977). Ainda, é importante mencionar que a filologia possui três funções, quais sejam:

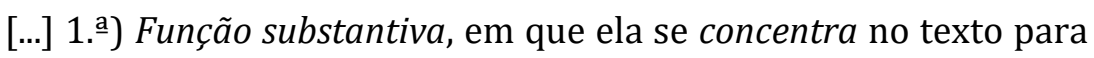
explicá-lo, restituí-lo à sua forma genuína e prepará-lo tecnicamente para publicação; 2..$^{-}$) Função adjetiva, em que ela deduz, do texto, aquilo que não está nele: a determinação de autoria, a biografia do autor, a datação do texto, a posição na produção literária do autor e da época, bem como a sua avaliação estética (valorização); 3. ${ }^{a}$ ) Função transcendente, em que o texto deixa de ser um fim em si mesmo da tarefa filológica, para se transformar num instrumento que permite ao filólogo reconstituir a vida espiritual de um povo ou de uma comunidade em determinada época. [...]. (SPINA, 1977, p. 77).

Diante dessas três funções, ressaltamos que nossa abordagem seguirá, principalmente, a função adjetiva, visto que ela se pauta em uma investigação literária, que engloba o todo de uma obra artística, e os resultados encontrados fazem parte de uma análise dedutiva do texto. A função adjetiva conta com o auxílio de outras ciências para identificar elementos que não estão no texto analisado, mas que são importantes para entendê-lo. Elementos como a biografia do autor, o período em que ele escreveu a obra literária, a datação do texto e outras versões do folheto podem nos levar a uma investigação filológica satisfatória, além de enriquecerem o trabalho propriamente crítico. 
A filologia, portanto, desempenha um papel muito importante na investigação de textos, ainda mais se observarmos as suas funções. Essa importância é lembrada por Mattos e Silva (2008), quando a autora discorre sobre a linguística histórica e o importante papel da filologia, uma vez que esta ciência cuida em analisar quais as melhores formas de abordar um documento escrito, seja ele literário ou documental. A autora ressalta a importância da crítica textual e como a filologia assume seu lugar como ciência do texto, e entender esses aspectos é fator crucial para que possamos analisar o corpus escolhido para essa pesquisa.

Nosso método pressupõe, ainda, reconhecer no texto suas regularidades de gênero discursivo. Nosso corpus, constituído por três folhetos, pertence ao gênero discursivo romance, entendido como um tipo secundário de gênero, de acordo com os preceitos bakhtinianos. Afirmamos que o folheto História da Donzela Teodora é um gênero discursivo secundário porque há a incorporação e reelaboração de gêneros primários, além de afastarem a imediaticidade que reúne enunciador e enunciatário na mesma cena (BAKHTIN, 2011).

A partir disso, podemos pensar na literatura de folheto, mais notadamente no folheto História da Donzela Teodora, como um continuum, em que a língua falada e a língua escrita estão profundamente ligadas, como pretendemos demonstrar na continuidade deste estudo e como afirma Porter (1993). Esse continuum, apontado por Porter, diz respeito ao fato de que certas formas da fala se aproximam da linguagem escrita, e que o contrário também pode acontecer. Por essa razão, propomos a abordagem filológica sob esse viés, dos gêneros orais aos gêneros escritos, em virtude do que há entre os dois, dessa linha de transmissão que liga um ao outro.

Algumas passagens extraídas do folheto podem revelar esse continuum. São elementos que costumam ser incomuns na forma da tradição escrita e acabam sendo recorrentes na tradição oral, como, por exemplo, a quebra da ordem direta da frase, com o fenômeno da inversão da palavra adjetiva. Logo, fenômenos como a inversão são frequentes e não causam estranheza na forma oral ${ }^{2}$, mas quando esse fenômeno aparece na tradição escrita reparamos a singularidade. É então que a linha de transmissão entre o gênero oral e o gênero escrito pode ser verificada:

\author{
$[\cdots]$ \\ Um húngaro conheceu nela \\ Formato de fidalguia \\ Mandou educal-a bem \\ Na melhor casa que havia \\ Em pouco tempo ela soube \\ 0 que ninguem mais sabia \\ [...] \\ Mas como tudo no mundo \\ E' mudável e inconstante \\ Esse rico mercador \\ Negociava ambulante \\ E toda sua fortuna
}

\footnotetext{
2 Um exemplo é a cantiga de roda <ciranda cirandinha/vamos todos cirandar/vamos dar a meia volta/volta e meia vamos dar>.
} 
Perdeu no mar num instante

[...]

Só via em torno de si

0 vil manto da mazela

Em casa só lhe restava

A mulher e a donzela

Então chamou Teodora

Pediu o parecer dela

[...]

Disse o mercador: El-rei

Não é cara esta donzela,

Dobrado a essa quantia

Gastei para ensinar a ela

Excede a todos os sábios

A sabedoria dela

[...]

(BARROS, 19--a, p. 2-8, grifos nossos)

A anteposição dos adjetivos verificada nas sextilhas acima tornou-se incomum na tradição escrita desde o século XVIII, conforme Cohen (1988), porque o português brasileiro estava em processo de eliminação gradual de inconsistências na língua, ou seja, de padrões como SOV (sujeito, objeto, verbo). Supomos que a preferência do autor por usar essa anteposição, que continua durante todo o folheto, pode ser um indicativo de erudição e, ainda de acordo com Cohen (1998), a permanência da anteposição do adjetivo pode ser percebida como um resquício de um padrão antigo latino ou indo-europeu. Dessa forma, "melhor casa", "rico mercador", "vil manto" e "não é cara esta donzela" ostentam o fenômeno do continuum, o entrelace entre oralidade e escritura. É legítima, entretanto, a ideia de que a oralidade não desconhece as inversões, sendo admissível que "melhor casa" ou "não é cara esta donzela" exemplifiquem um saber linguístico independente do domínio da estruturação sintática do campo da escrita. A ambiguidade mais reforça que afasta a ideia de continuum.

\section{OS DESAFIOS}

De acordo com o que trabalhamos até agora, percebemos que a literatura popular em verso possui traços da oralidade e isso pode repercutir quando analisamos filologicamente um texto com essas características: um continuum entre gênero oral e gênero escrito. Diante disso, surgem alguns desafios para a análise filológica do folheto História da Donzela Teodora, quais sejam a época em que o texto foi produzido, a linguagem e a corrupção do material. 0 nosso corpus é composto pelo folheto História da Donzela Teodora, a partir de 3 edições: a) a do próprio autor, Leandro Gomes de Barros (19--a); b) a de José Bernardo da Silva (19-b); e c) a de João Martins de Athayde (1947). 


\section{1. ÉPOCA EM QUE O TEXTO FOI PRODUZIDO}

0 primeiro desafio que examinaremos diz respeito à época em que o texto foi produzido, e a primeira edição do folheto não possui data, tampouco lugar de produção, logo, para que possamos chegar a um denominador comum, usaremos de algumas informações biográficas de Barros. Leandro Gomes de Barros era paraibano, nasceu em 1865 e mudou-se cedo para a Vila do Teixeira, lugar onde teve contato com cantadores e poetas até os 15 anos de idade. Após isso, Barros mudouse para outras cidades, agora pernambucanas, fixando-se no solo recifense, onde abriu uma pequena gráfica, em 1907, chamada Typografia Perseverança, que tinha o único objetivo de imprimir e distribuir seus folhetos (MINISTÉRIO DA CULTURA, 2019). Barros faleceu em março de 1918, de acordo com a obra intitulada Leandro Gomes de Barros: vida e obra, de Arievaldo Vianna (2014). Podemos, então, deduzir que a produção do folheto está compreendida entre os anos de 1880 e 1907, pois consideramos o período inicial em que Barros teve contato com poetas como válido para a produção do folheto.

Os folhetos de Barros começaram a circular, portanto, no século XX, e alcançaram todo o Nordeste e, de acordo com análise dos folhetos disponibilizados pela Biblioteca Virtual Folheto (2021), da Université de Poitiers, essa seria a capa da primeira publicação do folheto História da Donzela Teodora, cuja autoria e editoração é atribuída somente a Barros:

Figura 1 - Capa do folheto História da Donzela Teodora de Leandro Gomes de Barros (autoria e editoração)

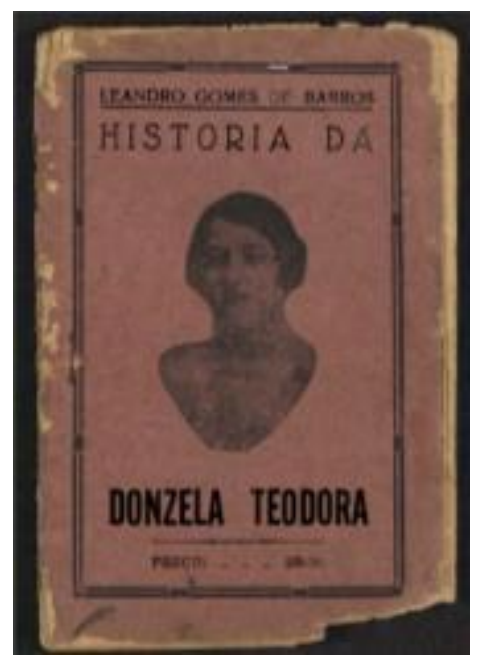

Fonte: BARROS, L. G. (19--a, não paginado).

Outra publicação do folheto, cuja autoria é atribuída a Leandro Gomes de Barros, foi editorada e distribuída na cidade de Juazeiro do Norte, com editoração de José Bernardo da Silva: 
Figura 2 - Capa do folheto História da Donzela Teodora de autoria de Leandro Gomes de Barros, e editoração de José Bernardo da Silva.

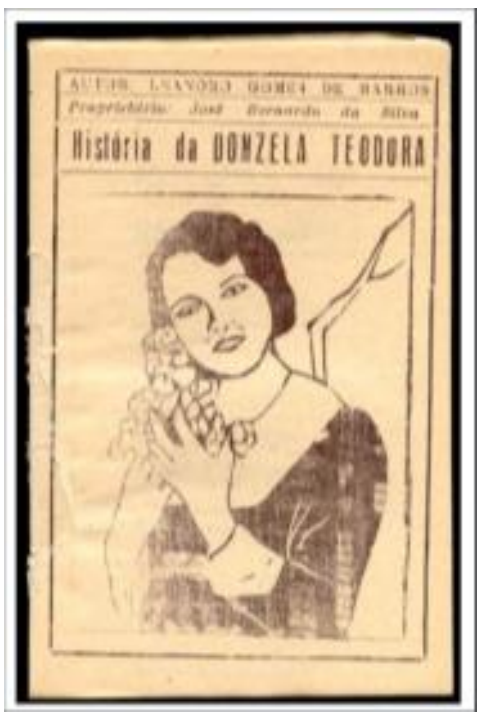

Fonte: BARROS, L. G. (19--b, não paginado).

Ainda há uma terceira publicação do folheto História da Donzela Teodora, mas esta não faz nenhuma menção ${ }^{3}$ à Leandro Gomes de Barros e somente o nome de João Martins de Athayde aparece na capa do folheto, o que dá a entender que ele é o autor da obra. Essa edição é problemática porque estudos sobre vida e obra de Barros indicam que Athayde adquiriu os direitos autorais de Barros em um negócio realizado com a esposa dele, após o falecimento do poeta, e desde então publicou obras de Barros, com modificações, sem fazer menção ao poeta (VIANNA, 2014):

Figura 3 - Capa do folheto História da Donzela Teodora de autoria de Leandro Gomes de Barros, e editoração de João Martins de Athayde.

\footnotetext{
${ }^{3}$ Independentemente de o folheto editorado por João Martins de Athayde não fazer menção ao autor, estudiosos do tema atribuem a autoria a Leandro Gomes de Barros, por ser dele a obra, e por essa razão adotamos o mesmo posicionamento em nossas citações e referências.
} 


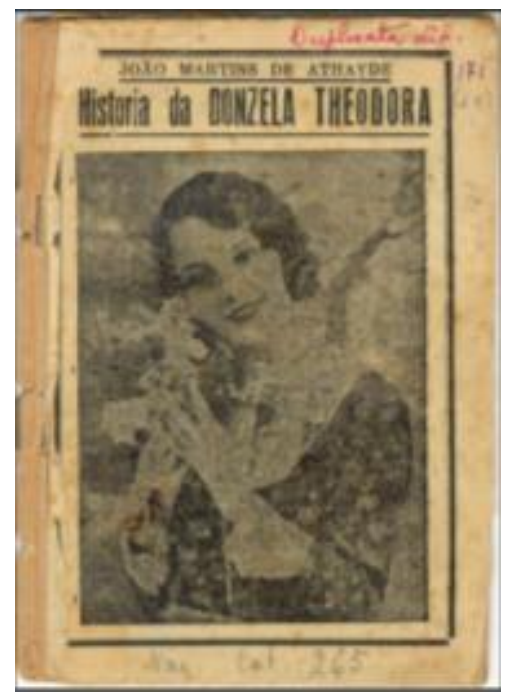

Fonte: BARROS, L. G. (1947, não paginado).

A edição feita por Athayde conta com as informações sobre lugar da publicação e data:

Figura 4 - Página 32 do folheto História da Donzela Teodora de autoria de Leandro Gomes de Barros, e editoração de João Martins de Athayde. <Fim-Recife, 13/7/1947 Preço 2 Cruzeiros>.

\section{Flm-Reelfe, 13/7/1947 Preço 2 Cruzeicos}

Fonte: BARROS, L. G. (1947, p. 32).

As imagens dos folhetos não fazem menção à data ou ao lugar, com exceção daquela editorada por Athayde, e esse fator constitui um desafio para as pesquisas filológicas, uma vez que fica inviável estabelecer a data exata em que o folheto foi elaborado, produzido e distribuído. É por essa razão que a filologia possui uma ligação íntima com outras disciplinas, como a história, por exemplo, que nos ajuda a delimitar o século em que o folheto foi produzido ou até mesmo o período temporal que apresentamos: 1880-1907.

\subsection{A LINGUAGEM}

Leandro Gomes de Barros foi criado por seu tio, que era padre, e por essa razão teve acesso a várias leituras, desde as Escrituras Sagradas à História de Carlos 
Magno e, já na fase adulta, teve acesso aos clássicos das literaturas portuguesa e brasileira (VIANNA, 2014). Esse aspecto biográfico nos direciona para uma investigação do uso da linguagem do poeta, e mais, denota aspectos culturais que influenciaram na produção do material. Como apontamos anteriormente, existe a versão da Historia de La Docta Simpatía (1916), de origem islâmica e traduzida para o espanhol, e a da História da Donzella Theodora em que se trata da sua grande fermosura e sabedoria (1740), traduzida para o português de Portugal. Seguindo o estudo de Vianna (2014), concordamos que é mais tangível que ele tenha tido contato com a obra de 1740, já que ela estava entre as obras literárias a que ele tinha acesso.

Assim, pretendemos analisar o uso da linguagem no folheto escrito, editorado e publicado por Leandro Gomes de Barros (19--a), no folheto editorado e publicado por José Bernardo da Silva (19--b) e no folheto editorado e publicado por João Martins de Athayde (1947). 0 uso da linguagem, portanto, é o segundo desafio para uma análise filológica do corpus, vez que os folhetos apresentam diferenças quanto ao uso de alguns termos, e as diferenças entre os folhetos citados podem ser encaixadas no que Cambraia (2005) chama de modificações endógenas. Como mencionamos em outro momento, essas modificações decorrem da transposição do texto de um material para outro e, em linhas gerais, podem ser autorizadas ou não pelo autor da obra.

Passaremos agora a analisar o corpus extraído dos folhetos que, para uma abordagem didática, trataremos da seguinte forma: História da Donzela Teodora I - autoria, editoração e publicação de Leandro Gomes de Barros (19--a); História da Donzela Teodora II - editoração e publicação de José Bernardo da Silva (19--b); e História da Donzela Teodora III - editoração e publicação de João Martins de Athayde (1947):

Figura 5 - História da Donzela Teodora I.

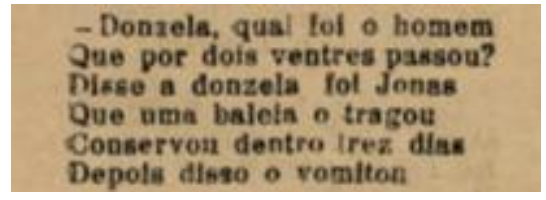

Fonte: BARROS, L. G. (19--a, p. 23).

Figura 6 - História da Donzela Teodora II.

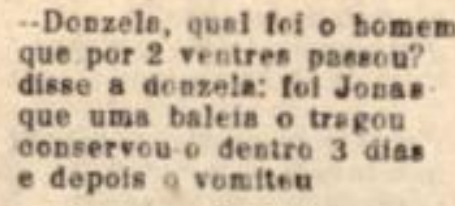

Fonte: BARROS, L. G. (19--b, p. 23). 
Figura 7 - História da Donzela Teodora III.

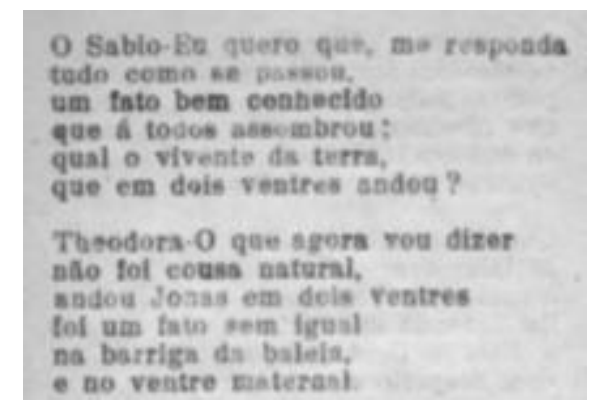

Fonte: BARROS, L. G. (1947, p. 25).

Os trechos apresentados retratam o episódio em que a Donzela Teodora responde uma pergunta-charada a um dos sábios e a resposta gira em torno da história bíblica de Jonas e a baleia. Podemos perceber que os três excertos abordam o mesmo momento, mas alguns aspectos linguísticos são modificados. Tomaremos como base a Figura 5, História da Donzela Teodora I, para analisarmos as Figuras 6 e 7.

Entre a imagem História da Donzela Teodora I e História da Donzela Teodora II notamos algumas sutis modificações, como, por exemplo:

1. a utilização de letras minúsculas em História da Donzela Teodora II e letra maiúscula apenas no primeiro verso, enquanto em História da Donzela Teodora I há maiúsculas no início de todos os versos;

2. a mudança do nome <dois $>$ para o número arábico $<2>$ e do nome $<$ três $>$ para o número arábico $<3>$;

3. o uso de <: > após <disse a Donzela $>$;

4. a mudança de <Conservou > para < conservou-o>, com a adição do pronome oblíquo átono;

5. o acréscimo da conjunção <e > e a retirada da contração < disso >.

Essas modificações são consideradas endógenas, de acordo com o pensamento de Cambraia (2005), pois são resultado da passagem de um material para outro. Podemos perceber, ainda, a presença de modificações não autorais, mesmo que sutis, que vão desde a escolha por iniciar somente o primeiro verso com letra maiúscula, até a inclusão de uma pontuação que não existia na versão original. O editor do folheto História da Donzela Teodora II parece investir em uma versão mais econômica e de linguagem mais objetiva para o seu leitor.

Modificações mais acentuadas estão no folheto História da Donzela Teodora III, em que podemos perceber não só acréscimo ou retirada de termos, mas uma verdadeira mudança na contação da história de Jonas e a baleia. Há a fala do sábio em seis versos e a fala de <Theodora>, com h e sem $0<$ Donzela $>$, também com seis versos. Essa edição parece querer mostrar mais detalhes ao leitor, não tem o caráter econômico e direto da outra. História da Donzela Teodora III, com 
modificações que podem ser encaixadas como endógenas e não-autorais, foi produzida e distribuída bem depois, em 1947.

É importante apresentar outra passagem que repete os mesmos problemas de modificação de forma mais ostensiva, principalmente a que aparece na Figura 10. A temática dos trechos gira em torno da cena que relata a aposta feita entre a Donzela Teodora e o último sábio:

Figura 8 - História da Donzela Teodora I.

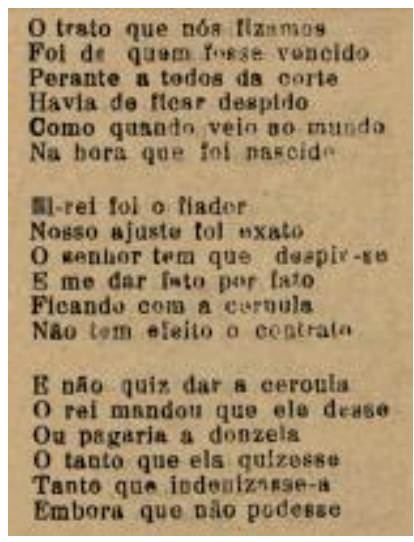

Fonte: BARROS, L. G. (19--a, p. 29).

\section{Figura 9 - História da Donzela Teodora II.}

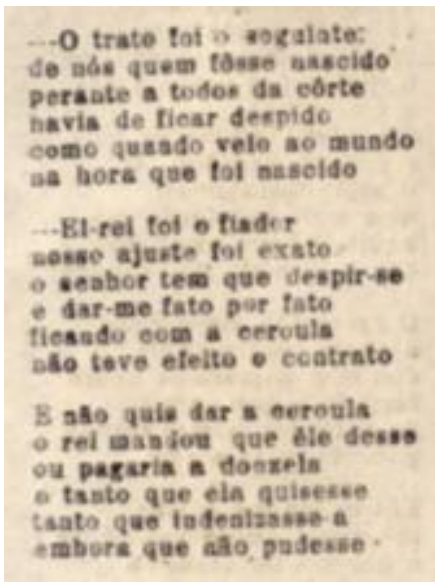

Fonte: BARROS, L. G. (19--b, p. 29).

Figura 10 - História da Donzela Teodora III. 


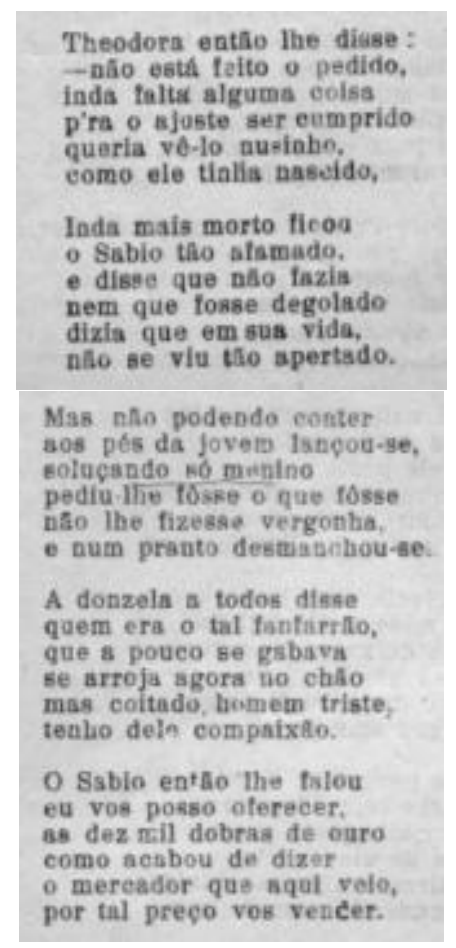

Fonte: BARROS, L. G. (1947, p. 28-29).

Percebemos que a História da Donzela Teodora II continua com as mesmas modificações sutis, acrescenta ou retira algum termo/pontuação, com o aparente objetivo de dar mais economicidade aos versos ou de fazer com que a narrativa seja mais direta. Essa versão apresenta um erro que parece ser inocente, pois há a palavra $<$ nascido $>$ no lugar de $<$ vencido $>$, quando evidentemente a palavra deve ser $<$ vencido $>$ para que faça jus ao que está sendo contado.

Em contrapartida, em a História da Donzela Teodora III notamos uma narrativa mais extensa, com detalhes que não estão em História da Donzela Teodora I. Nesta, por exemplo, a ideia de pagar à Donzela surge do rei, e naquela a ideia surge do próprio sábio. Ainda, a linguagem atribuída à Donzela parece ser menos polida em História da Donzela Teodora III. Se pegarmos, por exemplo, as expressões "queria vê-lo nusinho" (1947, p. 28) e "havia de ficar despido" (19--a, p. 29) podemos pensar que tanto a época, quanto a mudança de trato com a narrativa podem ter influenciado nessa mudança brusca no modo de falar da personagem. Parece correto sugerir que em 1947 era aceitável que uma mulher utilizasse um termo menos polido para se referir à nudez, enquanto na época em que a primeira edição foi produzida, era melhor que fosse feito o uso de termos mais polidos. Se compararmos, portanto, as sextilhas da Figura 10 e as sextilhas da Figura 8, chegaremos à conclusão de que não foi a mesma pessoa que construiu aquela narrativa, não só pela mudança brusca do modo de falar dos personagens, mas também pelo novo direcionamento que a obra apresenta.

O corpus extraído da História da Donzela Teodora II parece ser fiel à história mobilizada por Barros, ainda que haja alguma modificação feita pelo editor, pois não há mudança brusca na linguagem dos personagens, nem na narrativa. As 
mudanças mobilizadas pelo editor dessa versão parecem ter a intenção de causar uma maior fluidez na leitura, fazer com que os versos sejam mais objetivos. Em a História da Donzela Teodora III o objetivo do editor parece ser outro, pois a narrativa não guarda qualquer relação direta com a de Barros (salvo o conteúdo), que primeiro mobilizou a História da Donzela, e a impressão que fica é que o editor dessa versão buscou camuflar a autenticidade da autoria de Barros.

\subsection{CORRUPÇÃO DO MATERIAL}

Inúmeros fatores podem resultar na corrupção de um material. À título exemplificativo podemos citar a umidade, o calor, os insetos, a depredação, e esses fatores podem modificar um documento e dificultar a sua análise. Em História da Donzela Teodora I, a corrupção do material é mais evidente que nas outras versões, pois o documento já estava em processo de decomposição quando foi realizada a digitalização: trata-se de uma corrupção do material por motivos típicos, naturais, como podemos observar nas imagens que seguem:

Figura 11 - História da Donzela Teodora I: Corrupção do Material (Típica)

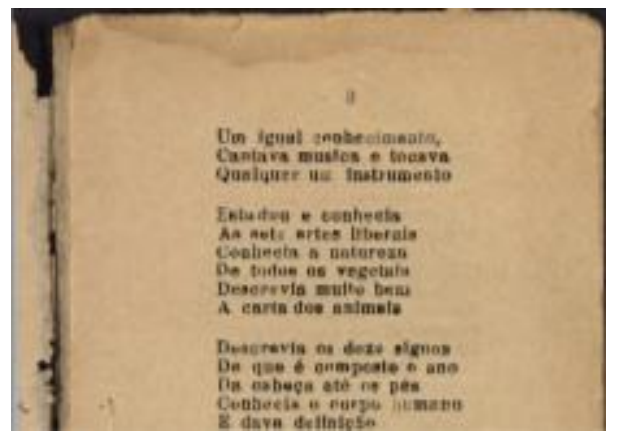

Fonte: BARROS, L. G. (19--a, p. 3).

Nessa imagem, podemos verificar vários tipos de corrupção do material: a decomposição das folhas, o apagamento das tintas por efeito do tempo e as bordas superiores com marcas de água. Algumas dessas corrupções comprometem o entendimento do documento, principalmente a do apagamento da tinta (exemplo disso é a Figura 5, que no lugar de <três > tem <.lres >. Essas corrupções podem ser resolvidas com o auxílio de outro material, uma outra versão ou outro documento de melhor conservação. Outros exemplos de corrução do material podem ser identificados na figura que segue:

Figura 12 - História da Donzela Teodora I: Corrupção do Material (Típica) 


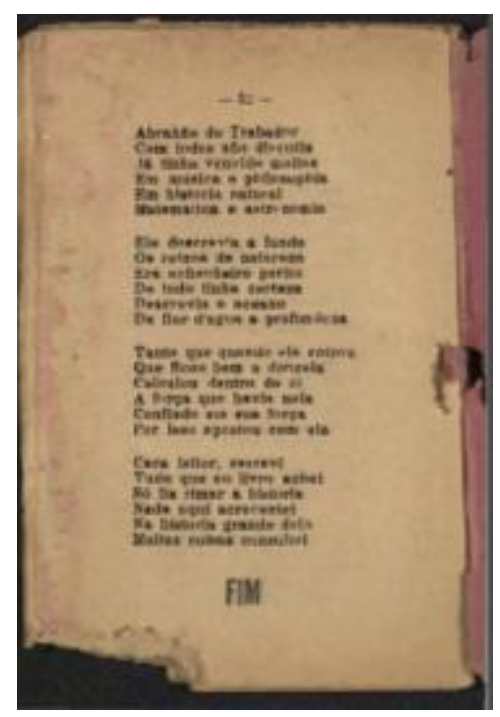

Fonte: BARROS, L. G. (19--a, p. 32).

Essa imagem demonstra que o contato da capa rosa com a água fez com que houvesse uma transposição dessa tintura para a página 32, além de percebermos alguns deterioramentos no canto inferior esquerdo, que podem ser resultado de uma depredação involuntária do material ou da ação de insetos. Materiais nesse estado apresentam desafios para a pesquisa filológica porque alguns elementos podem ser de difícil análise devido ao grau de corrupção que o material se encontra. Algumas passagens dessa edição são quase impossíveis de decifrar:

Figura 13 - História da Donzela Teodora I: Corrupção do Material (Típica)

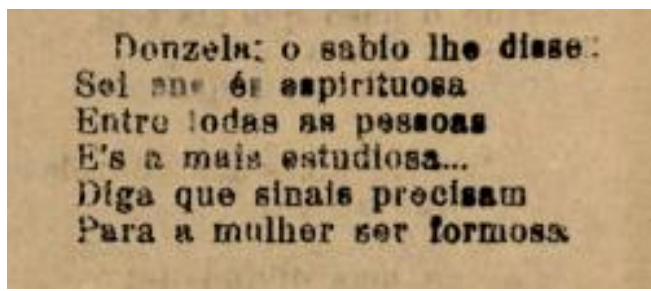

Fonte: BARROS, L. G. (19--a, p. 16).

0 que parece ser, no segundo verso, <an>, na verdade é <que>, se compararmos com a edição de José Bernardo da Silva:

Figura 14 - História da Donzela Teodora II. 


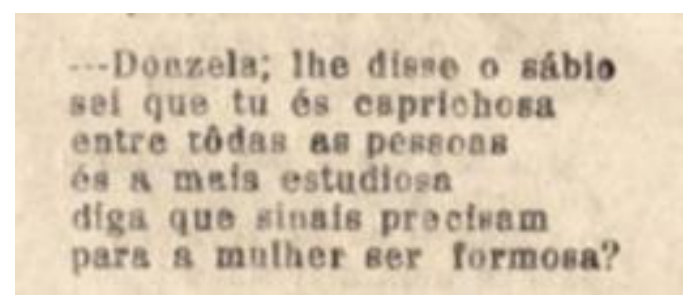

Fonte: BARROS, L. G. (19--b, p. 16).

Algumas corrupções do material podem ser resolvidas com estratégias de equiparação dos documentos para chegar a um denominador comum. É possível trabalhar com esse recurso ainda que a edição História da Donzela Teodora II mude algumas palavras (de <espirituosa>, para <caprichosa>, por exemplo), pois constatamos que a base permanece a mesma e uma comparação entre as edições pode revelar os termos corrompidos da primeira edição. Importa mencionar que não identificamos nenhuma corrupção do material atípica nos folhetos História da Donzela Teodora I, II e III, ou seja, corrupções que podem ser resultado de atos de vandalismo, como rasuras ou depredação do material que prejudiquem o conteúdo da obra.

\section{CONSIDERAÇÕES FINAIS}

O propósito inicial desse estudo foi demonstrar que não só é possível como extremamente necessário utilizar-se da ciência filológica para investigar aspectos vagos que cercam a literatura de folheto, mais precisamente o folheto História da Donzela Teodora. A filologia, como ciência que busca responder lacunas, desempenhou um papel proveitoso nessa pesquisa, pois o seu caráter transdisciplinar nos proporcionou unir várias áreas do saber para chegarmos a um denominador comum. A filologia também apresenta seus limites, que aqui chamamos de desafios, e esses estão no próprio objeto da pesquisa, no documento ou corpus e, às vezes, até o caráter transdisciplinar que ela possui não consegue nos ajudar a resolver os desafios encontrados.

Dessa forma, apresentamos os desafios que nos deparamos ao analisar o corpus: a época em que o texto foi produzido, a linguagem utilizada e a corrupção do material. Quanto à época em que os folhetos foram produzidos, mais precisamente aquele escrito e editorado por Barros (19--a), chegamos à conclusão que a sua elaboração foi feita no século XX, entre 1880 e 1907, de acordo com os aspectos biográficos que apontamos. Em relação à linguagem utilizada, constatamos que há importantes diferenças nos usos da língua a depender da editoração. 0 folheto editorado por Silva (19--b) segue um padrão linguístico similar ao de Barros (19-a), mas o folheto editorado por Athayde (1947) apresenta mudanças radicais no tocante à utilização da linguagem e à forma como a narrativa é desenvolvida. Percebemos que a corrupção do material mostrou ser um grande impeditivo para uma análise mais detalhada do corpus, pois fatores típicos como o tempo, a umidade, o calor e/ou insetos, podem estragar o material a ponto de este ficar ilegível. 
Ressaltamos, por fim, que ainda há muito o que se explorar dos folhetos de Barros, inclusive do folheto que compôs o nosso corpus, pois ele não só escreveu tudo que leu em um livro ou fez rimar a história. 0 poeta transformou um texto, originalmente em prosa, em um folheto com cento e quarenta e duas sextilhas e fez uso de uma linguagem acessível a todas as esferas da sociedade, cuja narrativa serviu de base para outras produções no meio. Ainda, constatamos em suas rimas o continuum do qual Porter (1993) fala, ou seja, o trabalho poético uniu gênero oral ao gênero escrito durante toda a narrativa. Analisar o folheto História da Donzela Teodora, com o amparo da ciência filológica, sobretudo à luz da função adjetiva, foi o objetivo dessa pesquisa, identificando os desafios que essa obra apresenta para a investigação, com o objetivo de refletir sobre eles e, na medida do possível, solucioná-los.

\section{Referências}

AUERBACH, Erich. Introdução aos estudos literários. Tradução de José Paulo Paes. São Paulo: Editora Cultrix, 1987.

AYALA, Maria Ignez Novais. Do manuscrito ao folheto de cordel: uma literatura escrita para ser oralizada. Leia Escola. Campina Grande, v. 16, n. 2, 2016.

Disponível em: http://revistas.ufcg.edu.br/ch/index.php/Leia/article/view/710. Acesso em: 04 mar. 2021.

COHEN, M. A. A. M. 0 posicionamento do adjetivo no sintagma nominal: um estudo diacrônico. Boletim do Centro de Estudos Portugueses. Belo Horizonte, v. 9, n. 12, 1988. p. 58-62. Disponível em:

http://www.periodicos.letras.ufmg.br/index.php/cesp/article/view/4443/4218. Acesso em: 04 mar. 2021.

BARROS, Leandro Gomes de. História da Donzela Teodora. [S. l.: s. n.], [19--a]. 32 p. Disponível em: http://cordel.edel.univpoitiers.fr/viewer/show/107\#page/n0/mode/1up. Acesso em: 06 fev. 2021.

BARROS, Leandro Gomes de. História da Donzela Teodora. Juazeiro do Norte: José Bernardo da Silva, [19--b]. 32 p. Disponível em:

http://www.dominiopublico.gov.br/pesquisa/DetalheObraForm.do?select_action= \&co_obra=5394. Acesso em: 07 fev. 2021.

BARROS, Leandro Gomes de. História da Donzela Theodora. Recife: João Martins de Athayde, 1947. 32 p. Disponível em:

http://rubi.casaruibarbosa.gov.br:8080/handle/20.500.11997/1755?locale=es. Acesso em: 14 fev. 2021.

CAMBRAIA, César Nardelli. Introdução à Crítica Textual. São Paulo: Martins Fontes, 2005. 
EL libro de las mil noches y una noche - Tomo Séptimo. Valencia: Editorial Prometeo, 1916. Disponível em:

https://bivaldi.gva.es/es/consulta/registro.cmd?id=2750. Acesso em: 20 fev. 2021.

FUNDAÇÃO CASA DE RUI BARBOSA. Biografia à moda da casa. Rio de Janeiro: 2021. Disponível em:

http://www.casaruibarbosa.gov.br/cordel/leandro_biografia.html\#. Acesso em: 07 fev. 2021.

HISTORIA da Donzella Theodora, em que se trata da sua grande fermosura e sabedoria. Tradução de Carlos Ferreira Lisbonense. Lisboa Ocidental: [s. n.], 1741. Disponível em: https://purl.pt/30799/3/\#/32. Acesso em: 20 fev. 2021.

MATTOS E SILVA, Rosa Virgínia. “Ouvir o inaudível”. In: MATTOS E SILVA, R. V. Caminhos da linguística histórica. São Paulo: Parábola Editorial, 2008. p. 7-26.

MINISTÉRIO DA CULTURA. Leandro Gomes de Barros: o Príncipe dos Poetas. Brasília: Ministério do Turismo, Secretaria Especial da Cultura, 2019. Disponível em: http://cultura.gov.br/leandro-gomes-de-barros-o-principe-dos-poetas/. Acesso em: 06 fev. 2021.

PORTER, Roy. Introdução. In: BURKE, P.; PORTER, R. (Org.). Linguagem, Indivíduo e Sociedade: história social da linguagem. Tradução de Álvaro Hattnher. São Paulo: Editora da Universidade Estadual Paulista, 1993. p. 13-37.

SILVA, Paulo Gracino da. Folhetarias, poetas resistentes e cordel biográfico. Orientadora: Carla Mary S. de Oliveira. 2019. 141 p. Dissertação (Mestrado em História) - Programa de Pós-Graduação em História do Centro de Ciências Humanas, Letras e Artes, Universidade Federal da Paraíba, Paraíba, 2019.

SPINA, Segismundo. Introdução à Edótica: Crítica textual. São Paulo: Cultrix, 1977.

TERRA, Ruth B. L. Literatura de folhetos: persistência de uma forma de comunicação popular. Texto-base para comunicação apresentada no IX Encontro Brasileiro de Comunicação Social, item IV por uma memória da documentação popular, Painel "Usos e abusos da literatura de cordel". (mimeo.) apud AYALA, Maria Ignez Novais. Do manuscrito ao folheto de cordel: uma literatura escrita para ser oralizada. Leia Escola. Campina Grande, v. 16, n. 2, 2016. Disponível em: http://revistas.ufcg.edu.br/ch/index.php/Leia/article/view/710. Acesso em: 04 mar. 2021.

VIANNA, Arievaldo. Leandro Gomes de Barros: vida e obra. Fortaleza: Edições Fundação Sintaf/ Mossoró-RN: Queima-Bucha, 2014. 
ZUMTHOR, Paul. A letra e a voz: a literatura medieval. Tradução de Amálio Pinheiro e Jerusa Pires Ferreira. São Paulo: Companhia das Letras, 1993.

Para citar este artigo

GOMES, J. E. S. Os desafios da filologia no cordel História da donzela Teodora. Macabéa - Revista Eletrônica do Netlli, Crato, v. 10, n. 4, 2021, p. 146-164.

A Autora

JODIE ELLY SILVA GOMES é bachar ela em Direito pelo Centro Universitário Paraíso - UniFAP, pós-graduada em Direito e Processo Tributário (URCA), graduanda no curso de Letras, dupla habilitação em Língua Inglesa e suas Literaturas (URCA), mestranda em Letras pelo PPGL-URCA e estudante pesquisadora do Núcleo de Estudos de Teoria Linguística e Literária (NETLLI). 